\title{
Common Evolution of Mechanical and Transport Properties in Thermally Cracked Westerly Granite at Elevated Hydrostatic Pressure
}

\author{
M. H. B. Nasseri, ${ }^{1}$ A. Schubnel, ${ }^{2}$ P. M. Benson, ${ }^{1,3}$ and R. P. Young ${ }^{1}$
}

\begin{abstract}
Increasing the damage and crack porosity in crustal rocks can result in significant changes to various key physical properties, including mechanical strength, elastic and mechanical anisotropy, and the enhancement of transport properties. Using a Non-Interactive Crack Effective Medium (NIC) theory as a fundamental tool, we show that elastic wave dispersion can be inverted to evaluate crack density as a function of temperature and is compared with optically determined crack density. Further, we show how the existence of embedded microcrack fabrics in rocks also significantly influences the fracture toughness $\left(\mathrm{K}_{\mathrm{IC}}\right)$ of rocks as measured via a suite of tensile failure experiments (chevron cracked notch Brazilian disk). Finally, we include fluid flow in our analysis via the Guéguen and Dienes crack porosity-permeability model. Using the crack density and aspect ratio recovered from the elastic-wave velocity inversion, we successfully compare permeability evolution with pressure with the laboratory measurements of permeability.
\end{abstract}

Key words: Effective medium theories, transport properties, fracture toughness, thermal cracks, hydrostatic stress.

\section{Introduction}

The mechanical and transport properties of crustal rocks are profoundly influenced by cracks and pore spaces. The existence of embedded microcrack fabrics in rocks significantly influences the elastic moduli and inferred permeability (HEARD and PAGE, 1982), fracture toughness $\left(K_{I C}\right)$ (NASSERI et al., 2005, 2006 and 2008), elastic wave velocities (Reuschle et al., 2006; Schubnel and Guéguen 2003; Schubnel et al. 2006), and the permeability of rocks (GUÉGUEN and SCHUBnel 2003; BEnSON et al., 2006).

${ }^{1}$ Lassonde Institute, Department of Civil Engineering, University of Toronto, Toronto, ON, Canada. E-mail: Nasseri@ecf.utoronto.ca

${ }^{2}$ Laboratoire de Géologie, Ecole Normale Supérieure de Paris, CNRS UMR8538, 24 rue Lhomond, 75005 Paris, France.

${ }^{3}$ Rock and Ice Physics Laboratory, Department of Earth Sciences, University College London, Gower Street, London WC1E 6BT, U.K. 
The need for understanding of a coupled hydro-thermo-mechanical effect on fracture toughness, elastic properties and permeability in rocks is increasingly in demand. Seismic and velocity field data and its relation to complex, coupled phenomena is important and has a role in many applied engineering fields, such as enhanced oil production methods, hydro-fracturing, and the improved understanding of the stability of underground waste repositories (RUTQvist et al., 2005; ENGVIK et al., 2005). By performing controlled thermal cracking experiments, we investigate quantitatively the influence of thermal damage on fracture toughness, elastic wave velocity, and permeability. Until now, few experimental studies have been performed on the effect of thermal cracking on the mechanical strength, $K_{I C}$ and permeability of granitic rocks together. A small number of studies have successfully measured an in-situ $K_{I C}$ data, which shows a strong dependence upon other rock physical parameters, such as elastic-wave velocities and permeability (Meredith and AtKinson, 1985; Darot et al., 1992; Balme et al., 2004; FunAtsu et al., 2004). Conversely, however, measurements of heat-treated specimens after cooling (ATKINSON, 1984) have suggested that embedded microcrack fabrics in rocks significantly influence both elastic-wave properties and permeability (Simmons and Brace, 1965; Kern, 1978, 1997). NASSERI et al. (2007) studied the coupled evolutions of fracture toughness and elastic wave velocities at high crack density in thermally treated Westerly granite and used a noninteractive crack theory to predict $K_{I C}$ relatively well at high crack density and therefore will not focus on the said subject in the present study. Recently, BENSON et al. (2006) used inverted elastic-wave velocities inversion and permeability models of GuÉGUEN and DiENEs (1988) to predict the evolution of permeability with increasing pressure, from elastic-wave velocity variations.

Despite the fact that fractures generally represent only small amounts of porosity, the theoretical evolution of elastic properties with damage can generally be predicted using models developed in the framework of Effective Medium Theory (EMT), (e.g., O’Connell and Budiansky, 1974; Cheng and Toksöz, 1979; Kachanov, 1994; SAYers and Kachanov, 1995; Le Ravalec and Gueguen, 1996; Mavko et al., 1999). These models are used in order to predict the material properties as a function of a single non-dimensional damage parameter, the crack density and/or the porosity. Although elastic-wave velocities and the fracture toughness are both known to decrease with microcracking and permeability to increase with the latter, few attempts have been made until now to link all the three properties and compare quantitatively their coupled evolution. The present study presents the following, experimental and modeling study on samples of thermally stressed (up to $850^{\circ} \mathrm{C}$ ) Westerly granite: i) the experimental evolution of fracture toughness and elastic-wave velocities under a dry unconfined state for a series of chevron notched Brazilian discs, (ISRM, 1995); ii) the experimental evolution of permeability as a function of effective pressure up to $35 \mathrm{MPa}$, contemporaneously with the evolution of elastic-wave velocities up to $75 \mathrm{MPa}$ of effective pressure; and (iii) the theoretical evolution of permeability with increasing pressure, from elastic-wave velocity variations. 


\section{Experimental Methods and Procedures}

\subsection{Sample Selection}

Westerly granite was chosen in this study due to its evenly textured, isotropic initial microstructure (BRACE et al., 1968). In addition, the physical and mechanical properties of Westerly granite are well known, with numerous studies performed on this rock type over the years at elevated temperature and pressures (e.g., HADLEY, 1976; Heuze, 1983; Baure and Johnson, 1987; Thompson et al., 2006). Compositionally, Westerly granite is composed of $27 \%$ quartz, $36 \%$ microcline, $30 \%$ plagioclase, $6 \%$ phyllosilicates and $1 \%$ accessory minerals. The mean grain size is $0.75 \mathrm{~mm}$ with a total porosity of less than 1\% (Meredith and AtKinson, 1985). Two types of samples were prepared. Firstly, standard chevron notched Brazilian disc (CCNBD) of $75 \mathrm{~mm}$ diameter and $30 \mathrm{~mm}$ thickness for $K_{I C}$ measurement and, secondly, right cylindrical cylinders of $38 \mathrm{~mm}$ diameter and $78 \mathrm{~mm}$ length for permeability and elastic-wave velocity measurement.

\subsection{Experimental Methods}

Isotropic crack damage was generated in sixteen CCNBD samples and four cylindrical samples of Westerly granite (isotropic in nature) by thermally stressing the samples to temperatures of $250^{\circ} \mathrm{C}, 450^{\circ} \mathrm{C}, 650^{\circ} \mathrm{C}$ and $850^{\circ} \mathrm{C}$ at a rate of $1.5^{\circ} \mathrm{C} / \mathrm{min}$ using a standard laboratory furnace. After cooling at the same rate, azimuthal elastic-wave velocities $(\mathrm{Vp})$ were measured at an interval of $30^{\circ}$ circumferentially around each CCNBD specimen in order to confirm and measure the level of isotropic crack damage in each sample. Four samples were prepared at each temperature in the case of the CCNBD samples, with a single example at each temperature for the cylindrical samples. Notches were machined within the disc specimens only after this step, according to the standard ISRM (1995) procedure (Fig. 1). Four additional CCNBD and one cylindrical sample were not subjected to heating to provide an 'unfractured' room temperature (RT) example.

Fracture toughness was determined using the standard ISRM (1995) technique (Fig. 1) utilizing a stiff, servo-controlled loading machine to record displacement and force as each sample was loaded until failure at a constant rate of $0.01 \mathrm{~mm} / \mathrm{sec}$. Fracture toughness is given by:

$$
K_{I C}=\frac{P_{\max }}{B \sqrt{R}} Y_{\min }^{*},
$$

where $Y_{\min }^{*}=\mu . e^{\mathrm{Y} . \alpha 1} ; Y_{\min }^{*}$ is a critical dimensionless stress intensity value for the specimen, determined by the specimen geometry dimensions $\alpha_{0}, \alpha_{1}$ and $\alpha_{\mathrm{B}}$ (Fig. 1); $\mu$ and $\mathrm{Y}$ are constants determined by $\alpha_{0}, \alpha_{\mathrm{B}}$ (ISRM 1995, Table 2); $\mathrm{P}_{\max }$ is the maximum load at failure; $\mathrm{B}$ is the disc's thickness; and $\mathrm{R}$ is the radius of the disc. 


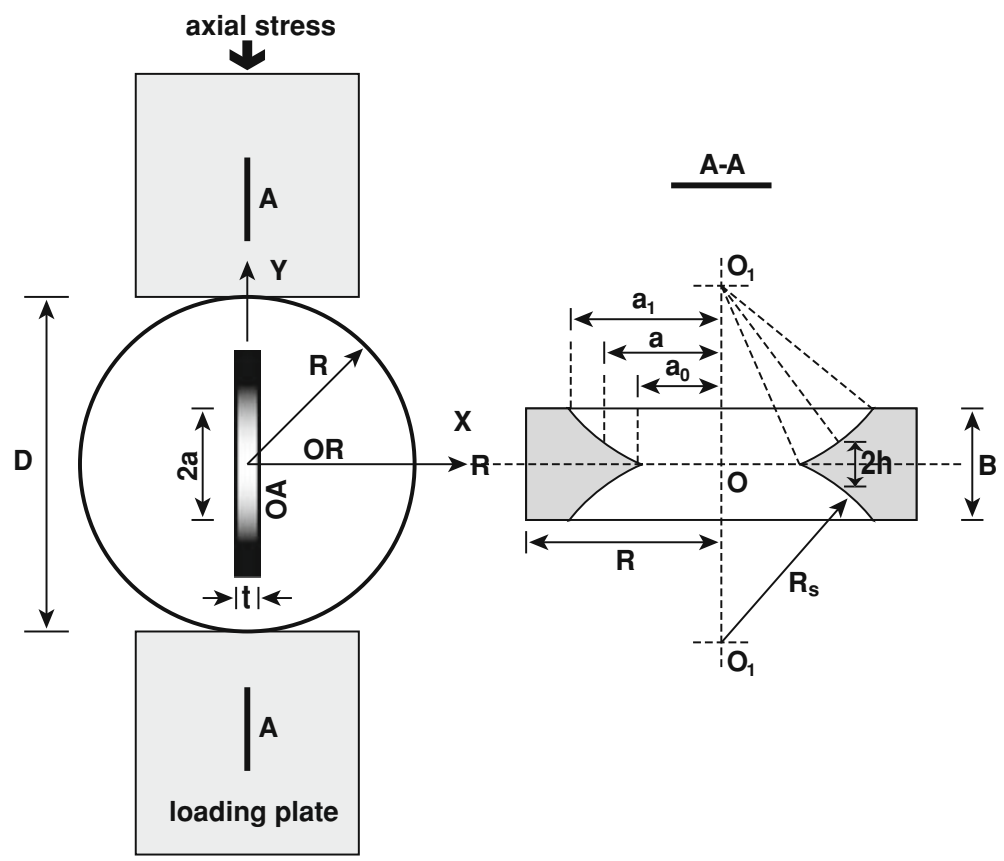

Figure 1

Geometry of the CCNBD and related parameters (after ISRM, 1995), $\mathrm{R}=$ Radius of disc; $\mathrm{B}=$ Thickness of disc; $\mathrm{D}=$ Diameter of disc; $\mathrm{R}_{\mathrm{S}}=$ Radius of saw; $a=$ Length of crack; $a_{0}=$ Initial half length of chevron notch; $a_{1}=$ Final half length of chevron notch.

Permeability was measured as a function of effective pressure $\left(\mathrm{P}_{\text {eff }}=\mathrm{P}_{\mathrm{c}}-\mathrm{P}_{\mathrm{p}}\right.$, where $\mathrm{P}_{\mathrm{c}}$ is the confining pressure, and $\mathrm{P}_{\mathrm{p}}$ is the pore pressure) up to $35 \mathrm{MPa}$. For cylindrical specimens thermally stressed to $450^{\circ} \mathrm{C}, 650^{\circ} \mathrm{C}$ and $850^{\circ} \mathrm{C}$, the steady-state flow method was used, whilst for the RT and $250^{\circ} \mathrm{C}$ samples, the pulse decay method of BRACE et al., (1968) was employed, due to the much lower sample permeability. Calibration of the two methods was made using the $450^{\circ} \mathrm{C}$ specimen tested at $2.5 \mathrm{MPa}$ of effective stress. At 2.5 $\mathrm{MPa}$ of effective stress for $450^{\circ} \mathrm{C}$ heat-treated specimen steady-state flow method was applied to measure permeability value and the result was compared to the permeability value obtained for a similar situation using the pulse decay method. This approach helps to calculate the water dead volume in the system which is an essential input parameter in the pulse decay method. Permeability was measured using a hydrostatic (instrumented Hoek-type cell made by Ergo Tech Ltd.) pressure vessel equipped with platens allowing fluid flow through the cylindrical sample (Fig. 2). Upstream and downstream pressures were maintained at approximately 5.5 to $4.5 \mathrm{MPa}$ respectively, using a high precision servo-controlled microvolumetric syringe pump (Quizix QX20 k) capable of measuring cumulative fluid volume. Using this setup allows permeability to be calculated via the application of Darcy's law (e.g., GuÉGUEN and 


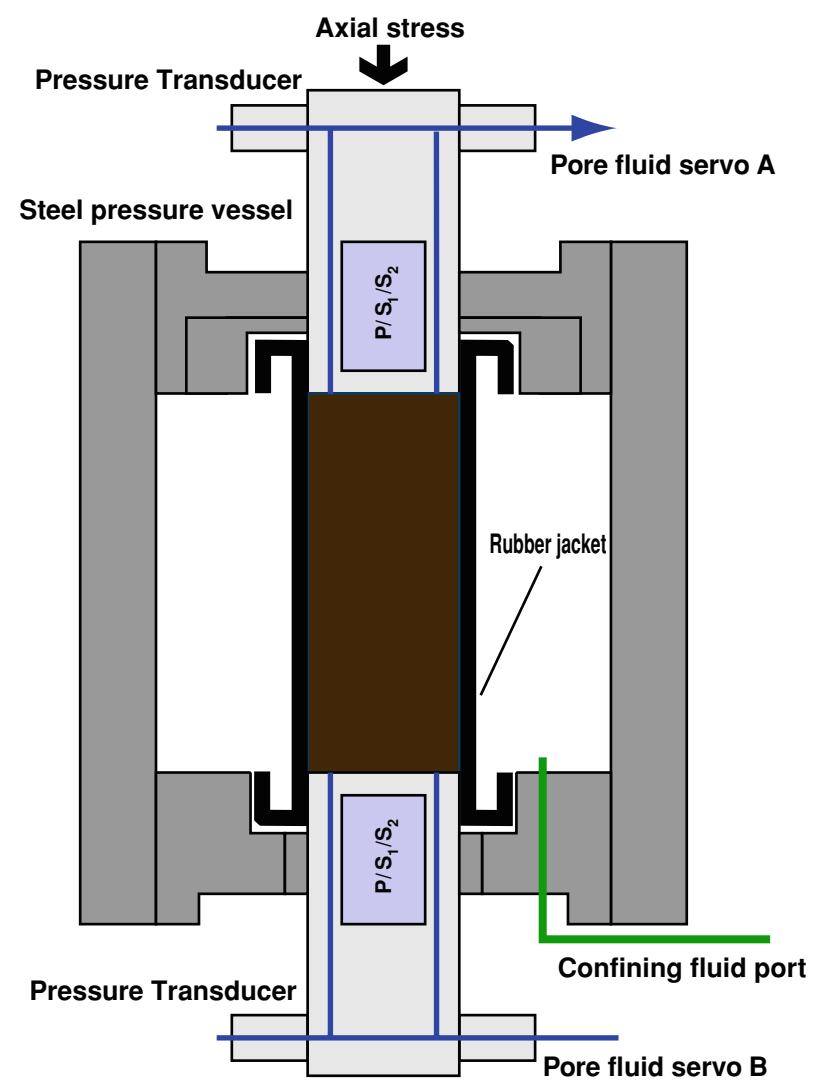

Figure 2

Hoek cell for measurement of contemporaneous permeability, elastic-wave velocity $\left(V_{p}, V s_{1}, V s_{2}\right)$ and porosity change as a function of effective pressure to $100 \mathrm{MPa}$.

PalciausKas, 1994). In addition, contemporaneous elastic-wave velocities $\left(V_{p}, V_{s}\right)$ are calculated axially using transducers embedded into the platens (Fig. 2). Elastic-wave velocities were measured up to effective pressures reaching $75 \mathrm{MPa}$. Finally, porosity change was determined at each step change in effective pressure by measuring the volume of pore volume expelled via the pore volumometers for all the heat-treated specimens. Permeability measurements were not continued beyond $35 \mathrm{MPa}$ of effective stress and the $K$ value was significantly reduced and application of the pulse decay method would take considerably longer and in practicality is not of great interest.

\subsection{Determination of Optical Microcrack Density, $\left(\rho_{\text {Optical }}\right)$}

Thin sections $(35 \mathrm{~mm} \times 22 \mathrm{~mm})$ perpendicular to the fracture propagation plane were made from the failed CCNBD specimens. Microstructural mapping, including 
intragranular and grain boundary microcrack mapping, and length measurements were conducted using digital images taken from the thin section. In order to be certain that this analysis was not affected by the crack propagation plane, these analyses were conducted at some distance from the thoroughgoing fracture (approximately $15 \mathrm{~mm}$ away from the area where test crack interacts with rock matrix). For intragranular crack measurement length HADLEY's (1976) definition of crack was applied where the crack's orientation does not deviate more than 20 degrees on any rolling $5 \mathrm{~mm}$ section of its length. A set cut off limit of $0.05 \mathrm{~mm}$ was selected for the crack length mapping from the optical images to ensure repeatability. Grain boundary microcrack lengths measurement involved unfolding of the curved boundaries into straight lines where the latter vary between 0.07 to $3.6 \mathrm{~mm}$ as the temperature for the specimens varied from room temperature to $850^{\circ} \mathrm{C}$. For specimens treated at 650 and $850^{\circ} \mathrm{C}$, where most of the grain boundary contacts were cracked, maximum grain boundary length could not exceed the perimeter of the maximum grain size. In addition to thin section analysis, scanning electron micrographs (backscatter) were also prepared, allowing the average widths of intragranular and grain boundary microcracks ( 50 measurements for each) to be directly measured as a function of thermal stressing temperature (NASSERI et al., 2007).

The analysis of the thin section and SEM images were performed using the program "Intercept" developed by LAUnEAu and RoBin (1996). This software allows the rapid determination of microcrack density by scanning images along sets of parallel lines, and counting the number of boundaries intercepted by those lines. The total number of intercepts is then converted into an optical crack density, expressed in $\left(\mathrm{mm} / \mathrm{mm}^{2}\right)$ which corresponds to the accumulated microcrack lengths $\left(a_{j}\right)$ from area $(A)$ using:

$$
\left(\rho_{\text {optical }}=\frac{\sum a_{j}}{A}\right) \text {. }
$$

\section{Experimental Results}

\subsection{Microstructural Analysis for RT and Heat-treated Specimens}

Figure 3 shows the evolution of both grain boundary $\left(\rho_{G B}\right)$ and intragranular microcrack $\left(\rho_{I G}\right)$ densities with temperatures reaching $850^{\circ} \mathrm{C}$ determined through optical microscopy. The initial ratio of $\rho_{I G} / \rho_{G B}$ (RT specimens) decreased from approximately 2.85 to approximately 1.73 and 1.25 for $250^{\circ} \mathrm{C}$ and $450^{\circ} \mathrm{C}$ specimens respectively due to the rapid increase in $\rho_{G B}$. This ratio attains a value of $\sim 1.54$ for $650^{\circ} \mathrm{C}$ specimens, reflecting the fact that intragranular density increased more than grain boundary crack density. Whereas this ratio reaches its lowest value of $\sim 0.95$ for $850^{\circ} \mathrm{C}$ specimens, reflecting a further increase in $\rho_{G B}$ especially observed due to the thermal splitting of individual quartz and feldspar minerals at $850^{\circ} \mathrm{C}$. A similar trend of observation has been reported by FREDRICH and WONG (1986) on thermal cracking of Westerly granite. 
Intragranular microcracks
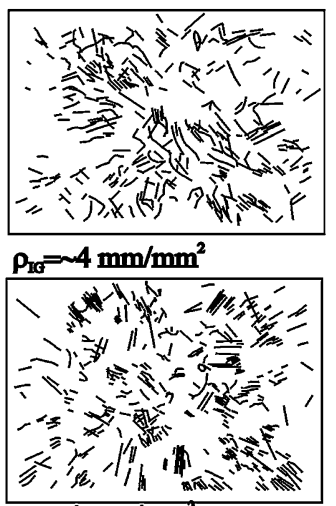

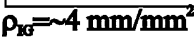

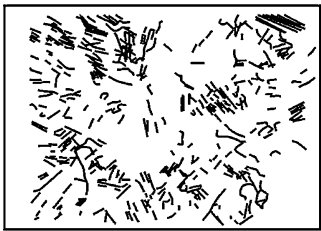

$\rho_{\mathrm{IG}}=\mathbf{m m} / \mathrm{mm}^{2}$

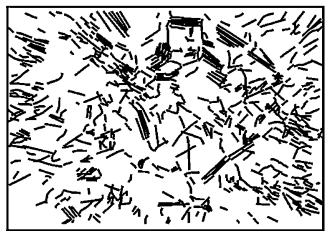

$\rho_{\mathrm{xc}}=-5.7 \mathrm{~mm} / \mathrm{mm}^{2}$

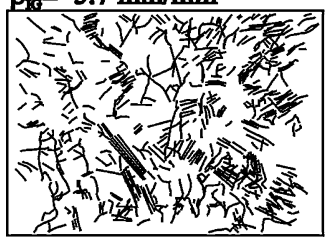

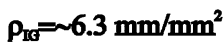

Grain boundary microcracks

RT

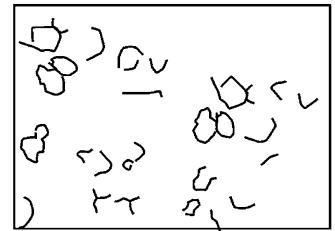

$\rho_{\mathrm{Cs}}=1.4 \mathrm{~mm} / \mathrm{mm}^{2}$

$250^{\circ} \mathrm{C}$

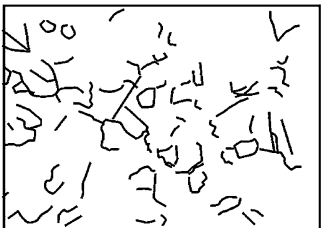

$450^{\circ} \mathrm{C}$

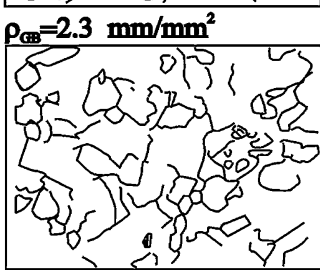

$\rho_{\mathrm{GB}}=3.2 \mathrm{~mm} / \mathrm{mm}^{2}$

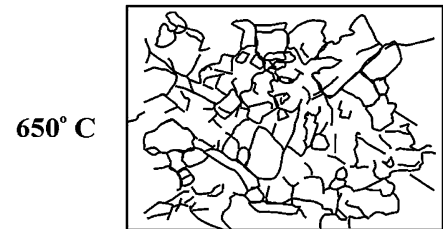

$\rho_{\mathrm{CB}}=3.7 \mathrm{~mm} / \mathrm{mm}^{2}$

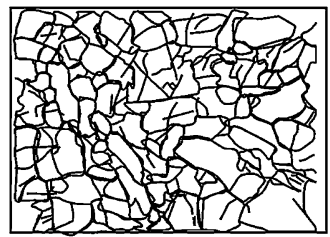

$1 \mathrm{~mm} \quad \rho_{\mathrm{aB}}=6.6 \mathrm{~mm} / \mathrm{mm}^{2}$

Figure 3

Variation of intragranular and grain boundary cracking density as a function of temperature in thermally-treated Westerly granite obtained using an optical method.

\subsection{Fracture Toughness and P-waves Velocity Evolution with Temperature}

Figure $4 \mathrm{a}$ shows the fracture opening displacement as a function of thermal stress level. There is a clear dependence on the damage level and both peak stress intensity factor $K_{1}$ (normalized to the peak fracture toughness of $1.48 \mathrm{MPa} \cdot \mathrm{m}^{0.5}$, measured in the RT sample) and maximum fracture displacement. A $60 \%$ reduction of the fracture 
toughness (from 0.98 to $0.43 \mathrm{MPa}^{0.5}$ ) is observed for the heat-treated specimens ranging from 450 to $650^{\circ} \mathrm{C}$. Figure $4 \mathrm{~b}$ displays the coupled evolution of $K_{I C}$ as a function of temperature treatment as compared to normalized P-wave velocities, as a proxy to damage level (normalized to RT specimen values). There is a clear negative correlation of $K_{I C}$ and normalized $V_{p}$ with thermal stressing temperature. However, the evolution of $K_{I C}$ and $V_{p}$ appears well coupled. Therefore, it is likely that $V_{p}$ is a good geophysical indicator of the deterioration of $K_{I C}$. The maximum P-wave velocity was measured in RT specimens $(4.55 \mathrm{~km} / \mathrm{s})$, which rapidly decreased to $0.94 \mathrm{~km} / \mathrm{s}$ at $850^{\circ} \mathrm{C}$. This corresponds to the $80 \%$ decrease in $V_{p}$, which compares favorably with the $85 \%$ decrease in $K_{I C}$. The biggest drop in velocity occurs between $450^{\circ} \mathrm{C}$ and $650^{\circ} \mathrm{C}$ as a result of the $\alpha-\beta$ quartz phase transition. In general, the peak stress becomes ill-defined beyond $650^{\circ} \mathrm{C}$ and is characterized with lower stress drops and increased post failure plasticity. These observations are in close agreement with the previous results obtained on Westerly granite (Heuze, 1983; Meredith and AtKinson, 1985).
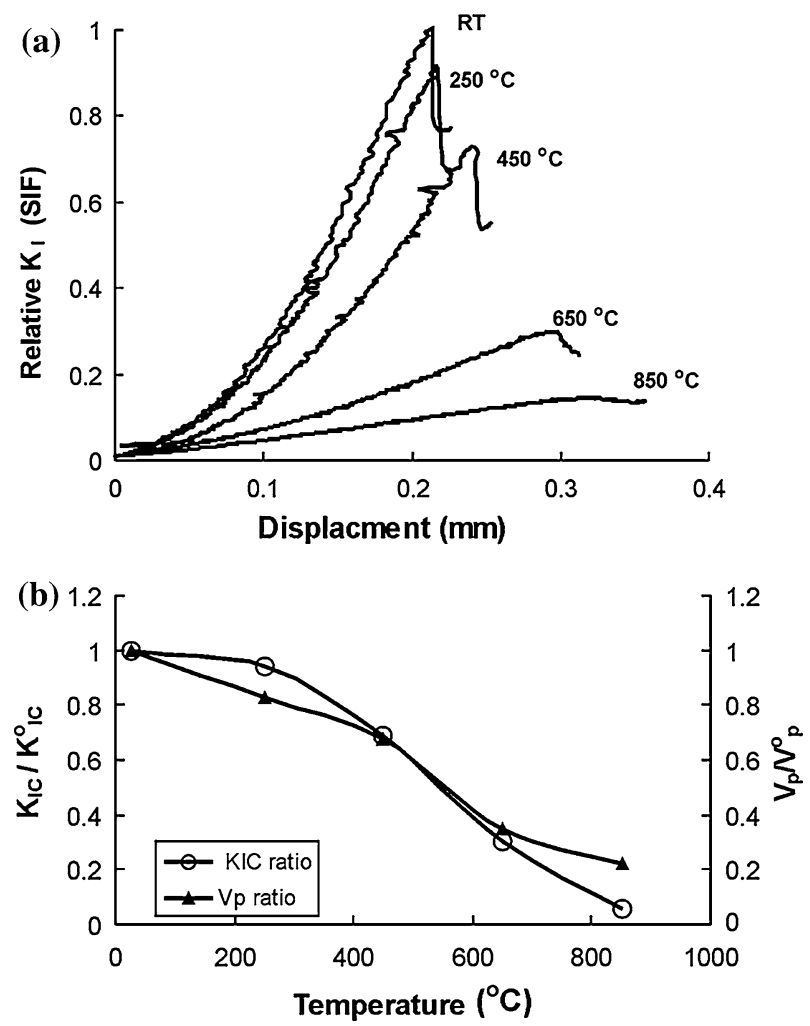

Figure 4

(a) Evolution of relative stress intensity factor $K I$, versus displacement, and as a function of temperature. (b) A comparison of the fracture toughness $\left(K_{I C}\right)$ and the mean P- wave velocity as a function of temperature treatment. Both $K_{I C}$ and the $V_{p}$ were normalized to that of the untreated specimens (after NASSERI et al., 2007). 


\section{Experimental Results: Elevated Isostatic Pressure}

\subsection{Permeability and Seismic Wave Velocities at Elevated Hydrostatic Pressure to $35 \mathrm{MPa}$}

Permeability was measured with an increasing effective pressure in a Hoek type triaxial cell equipped with an elastic-wave measurement system (shown in Fig. 2). Figure 5 shows that an approximately exponential decrease of permeability $(k)$ occurs with increasing effective pressure (where $\mathrm{P}_{\text {eff }}=\mathrm{P}_{\mathrm{C}}-\mathrm{P}_{\mathrm{P}}$ ), together with appreciable hysteresis during depressurization. The phenomenon of 'crack lips sticking' is thought to cause irreversible crack closure; this effect is more pronounced for the RT and heattreated specimens to $450^{\circ} \mathrm{C}$ as compared to the $650^{\circ} \mathrm{C}$ and $850^{\circ} \mathrm{C}$ specimens. This is best illustrated by reference to the change in elastic-wave velocity (both $V_{P}$ and $V_{S}$ ) shown in Figure 6. During pressurization, elastic-wave velocities increased as a response to crack closure, which, in turn, cause a concomitant reduction in permeability. During subsequent depressurization, the viscoelastic property of the microcracks dominates and therefore the complete restoration of permeability and elastic-wave velocities does not occur. The permeability decreases by an order of magnitude (from $4.13 \mathrm{E}-19 \mathrm{~m}^{2}$ to $4.9 \mathrm{E}-20 \mathrm{~m}^{2}$ ) as effective pressure increases from 2.5 $\mathrm{MPa}$ to $35 \mathrm{MPa}$ (RT specimen). However, this hysteresis (for RT specimen) is not as obvious when measured via the P-wave velocity, which returned to within $5 \%$ of its initial values. This trend is also seen for S-wave data

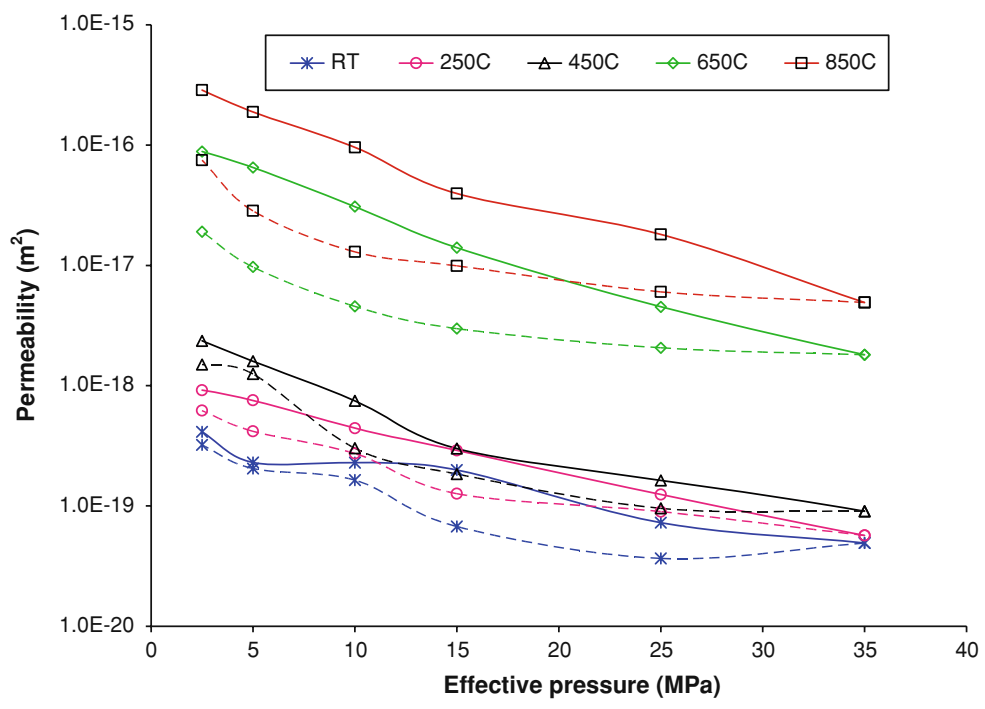

Figure 5

Variation of permeability ( $k$ in log values) with effective pressure for thermally-treated Westerly granite; the solid lines show the path during the pressurization cycle and the dashed lines show the path for depressurization cycles for different specimens. 
(Fig. 6b), which returned to within $4 \%$ more than their initial values. Whereas such a hysteresis in terms of $V_{p}$ and $V_{s}$ as a function of effective stresses for heat-treated samples, especially the second group, is quite distinguishable during depressurization.

For the specimens thermally stressed to $250^{\circ} \mathrm{C}$ and $450^{\circ} \mathrm{C}$, a similar trend was observed. However, there is considerable overlap with the RT data, and it is clear that the
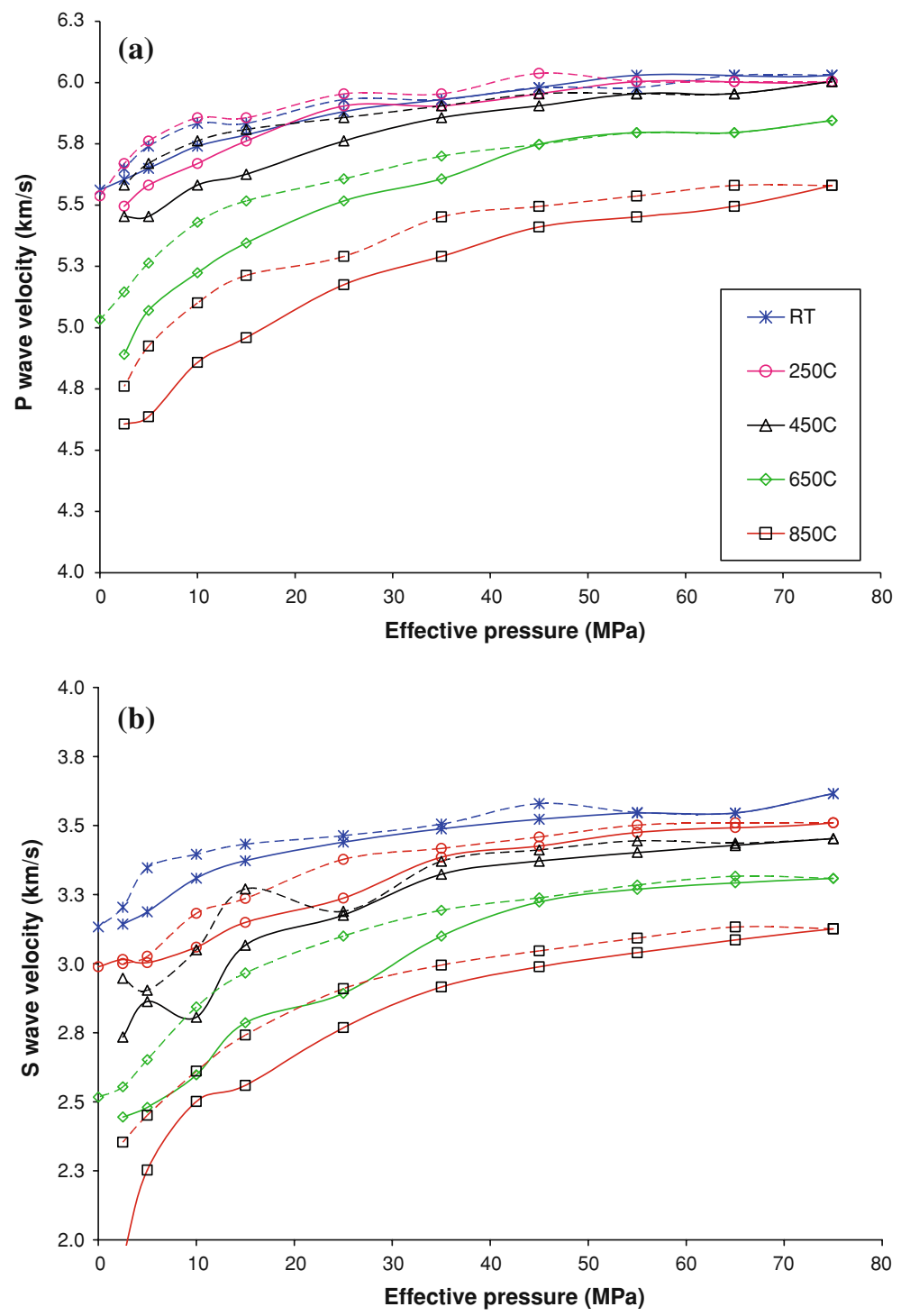

Figure 6

(a) Variation of measured $V_{p}$ and (b) $V_{s}$ with effective pressure for RT and thermally-treated specimens; the solid lines show the path during the pressurization cycle and the dashed lines show the path for depressurization cycles for different specimens. 
enhancement of permeability does not appreciably occur until a thermal stressing temperature threshold, at between $450^{\circ} \mathrm{C}$ and $650^{\circ} \mathrm{C}$, is crossed. $250^{\circ} \mathrm{C}$ and $450^{\circ} \mathrm{C}$ samples show a reduction in permeability with increasing effective pressure, decreasing respectively from $9.18 \mathrm{E}-19 \mathrm{~m}^{2}$ and $2.36 \mathrm{E}-18 \mathrm{~m}^{2}$ to $5.69 \mathrm{E}-20 \mathrm{~m}^{2}$ and $9.05 \mathrm{E}-20 \mathrm{~m}^{2}$. The P-wave velocity experiences an increase of approximately $\sim 7-8 \%$ during pressurization for both specimens. S-wave velocity for these two specimens increases about $19 \%$ for both specimens (Fig. 6). On depressurization, elastic-wave velocities returned to within 4-5\% above their initial values measured at $2.5 \mathrm{MPa}$ of effective stress. Variation of permeability for $650^{\circ} \mathrm{C}$ and $850^{\circ} \mathrm{C}$ specimens as a function of effective pressure up to $35 \mathrm{MPa}$ shows a reduction of one to two orders of magnitude respectively. $V_{p}$ and $V_{S}$ both increase $\sim 13 \%$ for $650^{\circ} \mathrm{C}$ specimen where as this increase for $850^{\circ} \mathrm{C}$ is about $13 \%$ and $35 \%$ respectively as function of effective stress rising up to $35 \mathrm{MPa}$. On depressurization, both elastic-wave velocities recover to within approximately 4-5\% more than their initial values, i.e., measured at $2.5 \mathrm{MPa}$ of effective stress before pressurization.

\section{Theoretical Analysis and Comparisons to Laboratory Data}

The effective mechanical and physical (elastic and transport) properties of an initially isotropic cracked medium depend on a number of key parameters combining linear fracture mechanics and statistical physics. In the present method, the following key parameters are defined:

- Fluid bulk modulus $\left(K_{f}\right)$ and matrix elastic properties with Young's modulus $E_{o}$ and Poisson ratio $v_{\mathrm{o}}$.

- Crack geometry (penny shaped cracks) with an average aspect ratio defined by: $\zeta=\langle w / 2 c\rangle$.

- Crack density $\rho$, defined by: $\rho=1 / V \sum_{0}^{N} c_{i}^{3}$, where $c_{i}$ is the radius of the $\mathrm{i}^{\text {th }}$ crack, $N$ being the total number of cracks embedded in the representative elementary volume $V$.

- Percolation factor $f$.

\subsection{Elastic Properties}

For an isotropic matrix containing a random distribution of cracks, the effective Young's modulus of a rock $E^{*}$ is a linear function of the crack density which can be written in the form (first perturbation order):

$$
\frac{E_{0}}{E^{*}}=1+H \rho
$$

A similar expression can be written for the effective shear modulus $\left(\mu^{*}\right)$. In equation (3), Young's modulus $E_{O}$ is that of the crack-free matrix, and $H$ is a positive scaling parameter which is dependent upon the matrix and fluid properties, the geometry of the 


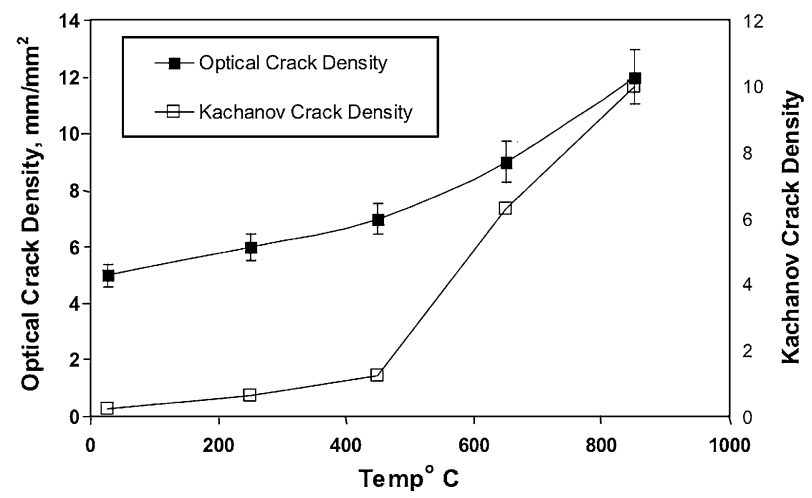

Figure 7

Crack densities determined optically and by P-wave velocity inversion as a function of temperature for the Westerly granite.

cracks and the interactions between them. The scalar $H$ has been calculated by many authors for a wide variety of crack geometries and fluid properties. In this work we use an appropriate and widely used scalar for non-interactive penny shaped cracks (Kachanov, 1994; Schubnel and GuÉGuen, 2003; Schubnel et al., 2006). One of the most straightforward methods is KACHANOV's (1994) non-interactive effective medium theory, as it neglects stress interactions between cracks, and can therefore represent a valid approximation for low crack densities (up to $\sim 0.5$ ). However, it is important to point out that above 0.5 , the calculation remains physical (the elastic moduli fall asymptotically to zero) such that the non-interactive theory remains a useful physical tool to quantitatively evaluate damage. Because we neglect stress interactions between cracks, calculations using the non-interactive approximation overestimate the actual crack density within the samples and in the following, we evaluate only an upper bound for crack density. More realistic values of crack density could be obtained using alternative effective medium theories taking into account stress interactions such as the Extended Differential Self Consistent scheme (Le Ravalec and Guéguen 1996). Comparing both theories at high crack densities would probably demonstrate that non-interactive theory continues to give physically interpretable results up to considerably higher crack densities than $\sim 0.5$. However, this last observation is beyond the scope of this paper.

In the present work we use the case of a random crack distribution (KACHANOv, 1994; SCHUBNEL and GuÉGUEN, 2003). When neglecting crack interactions, effective elastic moduli of a cracked solid can be calculated exactly and rigorously in a unique manner that depends solely upon the average crack orientation and distribution. For certain distributions, where stress interactions are compensating geometrically such as a random (isotropic) or aligned crack distributions, it was shown that the non-interactive approximation is the most effective scheme when compared to other effective media theories (Kachanov, 1994; Sayers and Kachanov, 1995). Moreover, in our case such a model is pertinent because cracks are elastically opening and closing due to isostatic 


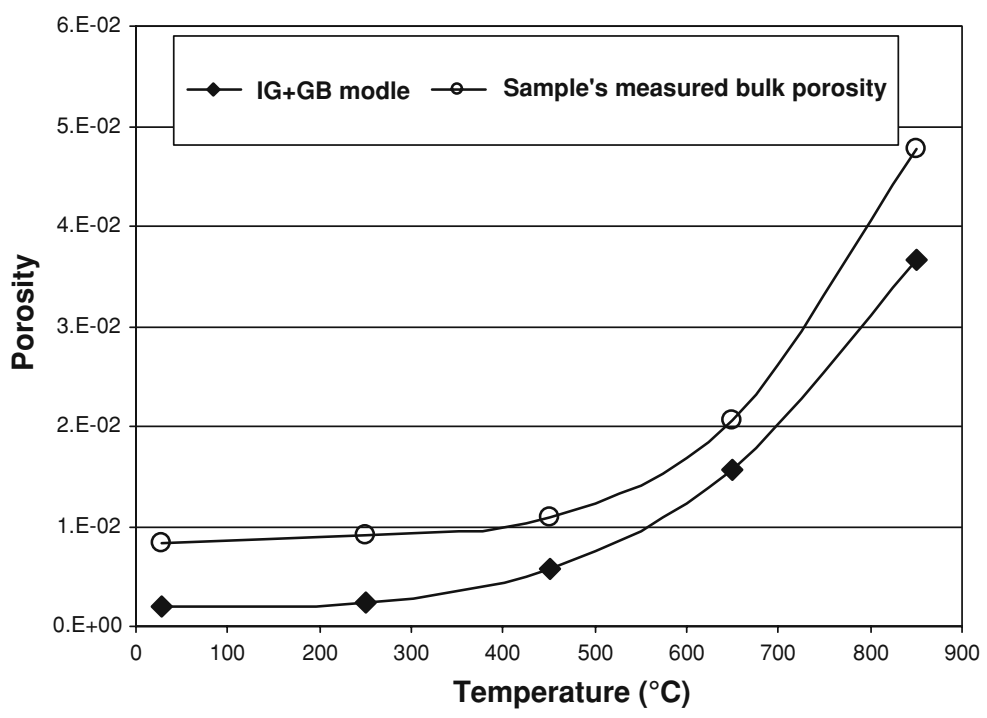

Figure 8

Comparison between sample's measured bulk porosity with microcrack porosity deduced form microstructural parameters (after NASSERI et al., 2007). IG = intragranular, $\mathrm{GB}=$ grain boundary microcracks.

pressure solely, whereas stress interactions are most important in the case of crack propagation only. In such a scheme, the evolution of elastic-wave velocities can be used to quantify uniquely both the crack density and aspect ratios. As all of these methods and concepts have been well discussed in previous publications (e.g., BENSON et al., 2006; SCHUBNEl et al., 2006), the precise details are not reproduced here.

\subsection{Dimensionless Microcrack Density, Inversion Method (KACHANOV)}

Figure 7 plots the dimensionless crack density $\rho$ as a function of temperature. As temperature increases, $K_{I C}$ decrease from 1.4 to $0.2 \mathrm{MPa}^{0.5}$, and $\rho$ increases from 0.26 to approximately 10 . The optically determined crack density $\rho_{\text {optical }}$, which is not a dimensionless parameter, is also plotted for comparison. Although $\rho_{\text {optical }}$ and $\rho_{\text {kachanov }}$ are correlated and show a very similar trend, it is hard to compare two parameters of different dimensions. In order to palliate to any misinterpretation this comparison could lead us to, microcrack aspect ratios $\zeta$ measured optically (using high resolution SEM images) were calculated by simply using $\zeta=\langle\mathrm{w}\rangle /\langle 2 \mathrm{c}\rangle$ where $w$ is the crack width and $c$ the crack radius. Remembering the fact that for penny-shaped cracks with constant aspect ratio distribution, the total microcrack porosity is also equal to $\phi=\pi \rho w / c$, then the aspect ratio can be expressed as a function of the porosity and the crack density, i.e., $\zeta=\phi / 2 \pi \rho$. Figure 8 shows the close comparison between the microcrack porosity as deduced from the microstructural parameter (shown in detail in NASSERI et al., 2007) with the porosity measured on the bulk samples as a function of temperature. Figure 9 shows 


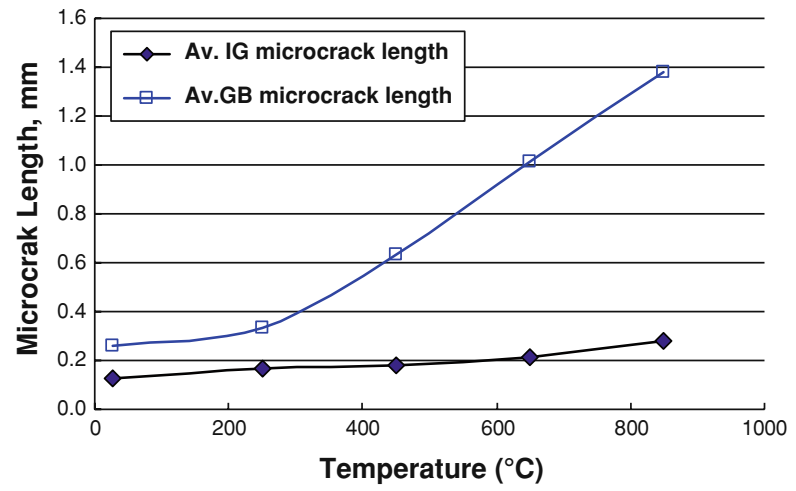

Figure 9

Evolution of intragranular and grain boundary crack length as a function of temperature at zero effective stress (measured from thin sections prepared for each heat-treated specimen).

the evolution of thermal crack length (intragranular and grain boundary) measured from a thin section prepared at various temperatures. Needless to emphasize that it is not physically possible to monitor such an evolution at various effective stresses and the responses of crack length to applied pressures.

\subsection{Simultaneous Inversion for Crack Porosity and Concomitant Permeability}

In order to link the effect of microcrack aspect ratio, density, and aperture to crack connectivity (and therefore permeability), the GUÉGUEN and DiENES (1989) crack permeability model may be employed. Any crack represents a void space of non-zero size, with the aperture being defined as the maximum width. If the cracks intersect, this will produce a crack permeability based on the fluid movement through the network of linked crack elements. GuÉGuen and DiEnEs (1989) quantify the effect of penny-shaped cracks on the permeability of an otherwise impermeable host matrix, and derived the following relation:

$$
k_{\text {cracks }}=\frac{1}{15} f_{\text {cracks }} w^{2} \zeta \rho,
$$

where, $\rho$ is the crack density, $w$ and $\zeta$ are the crack aperture and average aspect ratio (ratio of crack aperture to crack length), respectively, and $f_{\text {cracks }}$ is the percolation factor (Guéguen and Dienes, 1989; Schubnel and GuÉguen, 2003), approximated via:

$$
f_{\text {cracks }} \approx \frac{4}{9}\left(\frac{\pi^{2}}{4} \rho-\frac{1}{3}\right)^{2},
$$

and valid for $1 / 3<\rho \pi^{2} / 4<1$. In essence, $f_{\text {cracks }}$ describes the probability of two cracks intersecting $\left(\rho \pi^{2} / 4\right)$, in which case the volume element created by the intersecting cracks is discounted in the method (an excluded volume). In all cases, $0 \leq f_{\text {cracks }} \leq 1$. Here and 

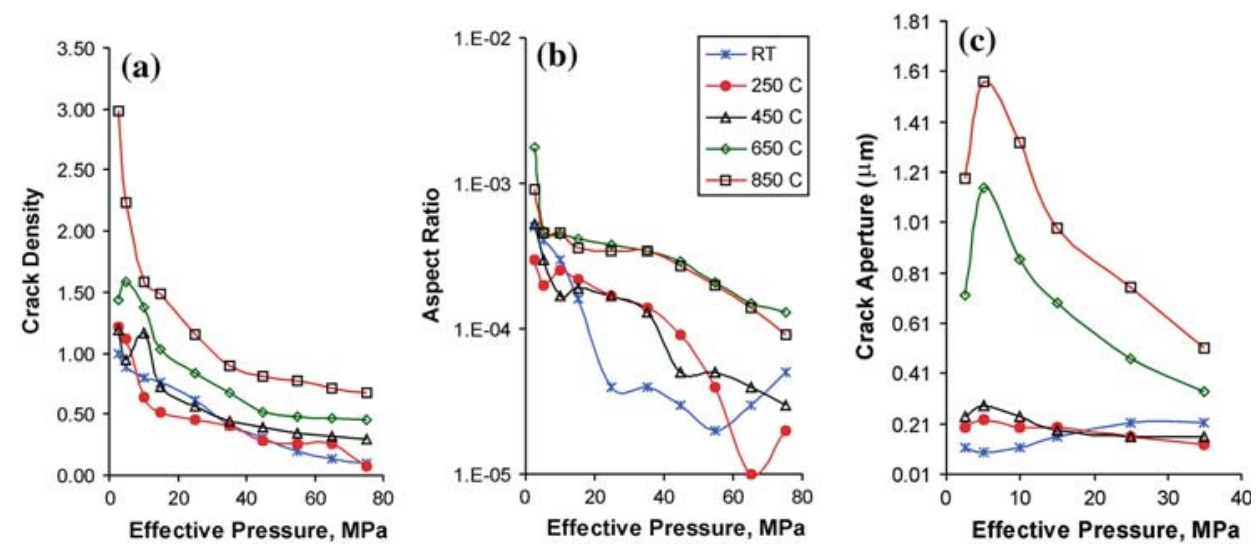

Figure 10

(a) Variation of crack density obtained from inversion of $V_{p}$ (b) aspect ratio and (c) crack aperture as a function of effective pressure measured in instrumented Hoek-type cell for RT and treated specimens.

for the sake of simplicity, we assume crack network to be always fully connected so that $f_{\text {cracks }}=1$ in all the following. As we shall see later, even a simple model can provide useful insight in helping estimate which factors dominate the bulk permeability and the permeability changes.

Figure 10 shows the variation of crack density, aspect ratio and crack aperture as a function of effective pressure for heat-treated and non-treated Westerly granite obtained from the inversion methodology explained above. The evolution of crack aspect ratio is shown up to $35 \mathrm{MPa}$ of effective pressure. All the mentioned properties respond to applied pressure with a decrease in magnitude. Figure 11 shows the comparison between the experimental and modeled values for $V_{p}, V_{s}$, porosity (up to $75 \mathrm{MPa}$ ) and permeability (up to $35 \mathrm{MPa}$ ) as a function of effective pressure. A detailed description of the said figures is included in the next section.

\section{Discussion and Interpretation}

Two groups of samples based on intensity of induced thermal damages are distinguished in this study. The first group of samples, treated up to $450{ }^{\circ} \mathrm{C}$, is characterized with a comparable range of data in terms of porosity, crack density, elasticwave velocities (including the nature of depressurization responses), fracture toughness and permeability (including the nature of depressurization responses) as a function of temperature. These properties are substantially different from the same properties shown by the second group of samples, which have been treated at $650^{\circ}$ and $850^{\circ} \mathrm{C}$ (Figs. 3 to 6 ). The modeled or predicted properties as well follow the similar overall trend with respect to the range of thermal treatment acquired in this study (Figs. 10 and 11). A similar trend 

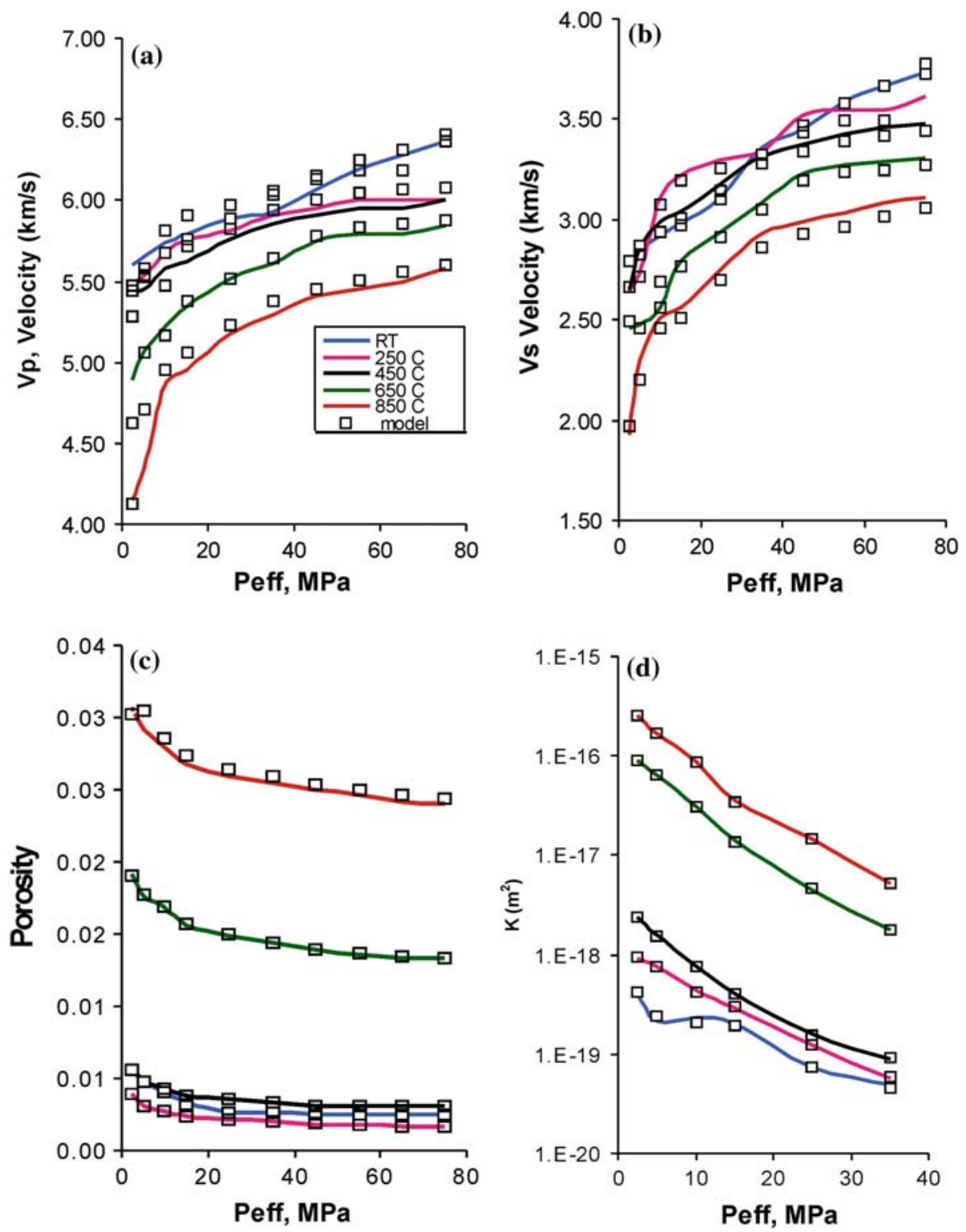

Figure 11

(a)Variation of experimentally determined and modeled $V_{p}$ (b) $V_{S}$, (c) porosity and (d) permeability $(k)$ as a function of effective pressure for RT and treated Westerly granite. The solid lines show the experimental values and square symbols show the modeled values.

of observations was noted in correlating between the fracture toughness and fracture roughness as a function of temperature for Westerly granite, (NASSERI et al., Fig. 8, this issue). Such a division based on distinctly different mechanical, physical and transport 
properties is directly related to the extend of thermal damages caused by $\alpha-\beta$ quartz phase transition in granitic rocks, (DAROT et al. 1992).

The stress intensity factor generated at the tip of propagating test crack (unconfined, dry specimens) drops $25 \%$ for the $450^{\circ} \mathrm{C}$ specimen in comparison to the $\mathrm{RT}$ specimen, whereas the stress intensity factor drops about $75 \%$ and $80 \%$ for the $650^{\circ} \mathrm{C}$ and $850^{\circ} \mathrm{C}$ specimens, respectively. Increased crack density above $\alpha-\beta$ quartz phase transition for the $650^{\circ} \mathrm{C}$ specimen and further enlargement of grain-grain boundary apertures at the $850^{\circ} \mathrm{C}$ specimens is responsible for lower resistance to cracking at the onset of test crack propagation. It has been concluded that during CCNBD testing, a macroscopic effective medium approach can grasp the reduction of $K_{I C}$ with crack density and might well explain the strong correlation observed experimentally between P-wave velocity and $K_{I C}$ reduction (NASSERI et al., 2007).

Figures $12 \mathrm{a}$ and $12 \mathrm{~b}$ show the evolution of porosity and P-wave velocities as a function of effective pressure for RT and thermally treated specimens. In this graph each measured value for porosity and $V_{p}\left(\Phi\right.$ or $\left.V_{p}\right)$ is divided by its corresponding values $\left(\Phi_{\mathrm{o}}\right.$ or $V_{p o}$ ) measured at $2.5 \mathrm{MPa}$ of effective pressure. Porosity in RT and treated specimens at $250^{\circ} \mathrm{C}$ and $450^{\circ} \mathrm{C}$ responds quickly to effective pressure increases, decreasing $55 \%-45 \%$ respectively up to $45 \mathrm{MPa}$ of effective pressure, followed with a more or less constant decrease up to $75 \mathrm{MPa}$ of effective pressure. This trend for $650^{\circ} \mathrm{C}$ and $850^{\circ} \mathrm{C}$ specimens follows a decrease of $25 \%$ and $15 \%$, respectively as effective pressure increases up to $75 \mathrm{MPa}$. P-wave velocity, on the other hand, increases linearly about $10 \%$ as a function of effective pressure for RT, $250^{\circ} \mathrm{C}$ and $450^{\circ} \mathrm{C}$ specimens whereas $650^{\circ} \mathrm{C}$ and $850^{\circ} \mathrm{C}$ specimens show a maximum increase of $20 \%$ and $35 \%$, respectively. It is shown that in the saturated specimens in the range of RT to $450^{\circ} \mathrm{C}$, induced thermal cracks which are characterized with lower crack density, smaller crack aperture and lower crack aspect ratio (Fig. 11), behave differently to the sets of samples treated at $650^{\circ} \mathrm{C}$ and $850^{\circ} \mathrm{C}$ when subjected to various levels of effective pressure. In the first group of specimens, thermal crack density being less $(\sim 1)$ and characterized with much lower aspect ratio $(\zeta,=\sim 5.00 \mathrm{E}-4)$ comply with the applied stress quickly, and as a result porosity drops instantaneously up to a threshold effective pressure in the range of $45 \mathrm{MPa}$. Whereas for the second range of specimens, characterized with high initial thermal crack density ( $\sim 2-3)$, much higher crack aspect ratio $(\zeta=\sim 2.00 \mathrm{E}-3)$ and bigger crack aperture $(0.5 \mu \mathrm{m})$ do not comply with applied pressure, immediately resulting in comparatively little porosity reduction (15\%-25\%) as a function of effective pressure. The variation of $V_{p}$ with effective pressure for the said two ranges of heat-treated rocks follows a similar trend. The first group of rocks show no large improvement in $V_{p}$ (Fig. 12b) with applied pressure during pressurization due to their lower porosity and lack of interconnected saturated pores, where as the second group of rocks show an increase (20\%-35\%) in $V_{p}$ with effective pressure increasing to $75 \mathrm{MPa}$. During depressurization, crack opening is delayed, suggesting irreversible closure of the cracks (Figs. 6a and 6b). Opening of cracks results in a larger $\mathrm{V}_{\mathrm{p}}$ and $\mathrm{V}_{\mathrm{s}}$ for the second group of rocks in comparison to first 

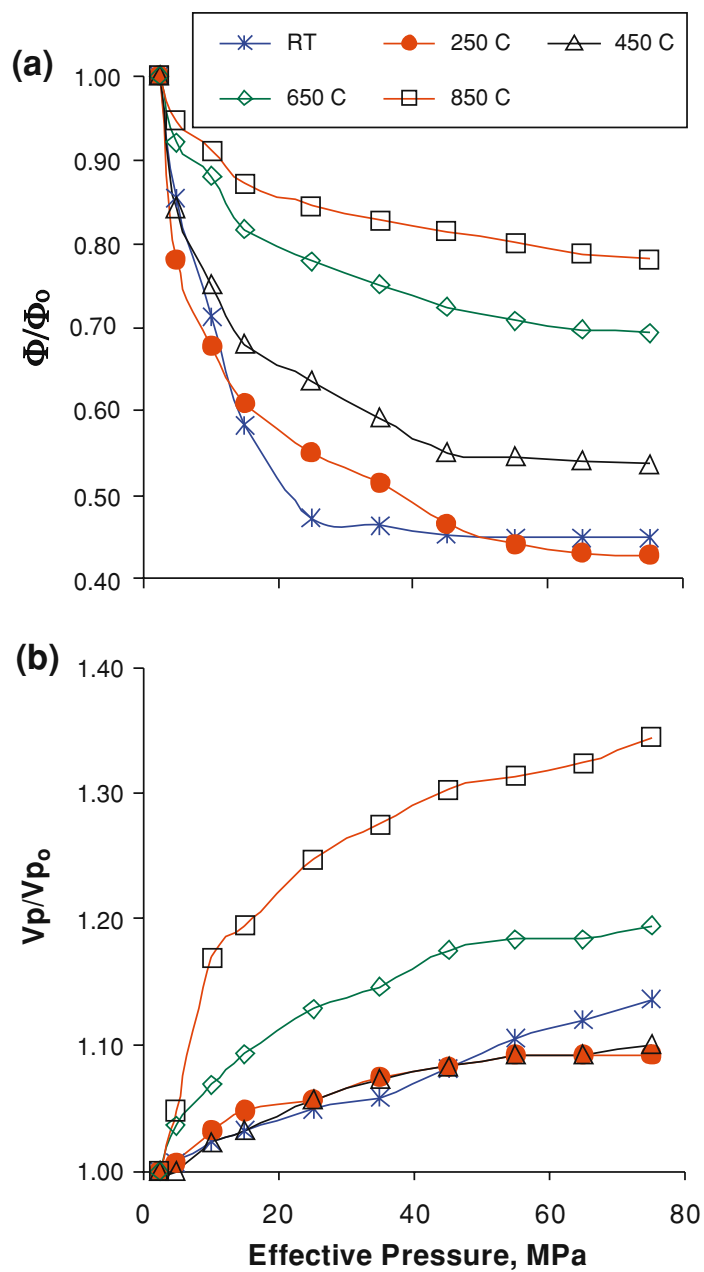

Figure 12

(a) Evolution of porosity and (b) P-wave velocities as a function of effective pressure for RT and thermallytreated specimens. In these graphs each measured value for porosity and P-wave velocity $\left(\Phi\right.$ or $\left.V_{p}\right)$ is divided by its corresponding lowest value ( $\Phi_{\mathrm{o}}$ or $V_{p o}$ ) measured at $2.5 \mathrm{MPa}$ of effective pressure.

group of rocks. Similarly the hysteresis between the closing and opening sequence is more pronounced for the second group of rocks than for the first group.

Figure 10 compares the experimental $V_{p}, V_{s}$, porosity and permeability with the modeled data during the pressurization sequence. Using the crack density and aspect ratio recovered from the elastic-wave velocity inversion together with the model of Guéguen and Dienes and initial porosity data; the recovered permeability variation can be mapped (Fig. 11d) with pressure. Increase of elastic-wave velocities due to pressure is large and controlled by crack density for specimens RT $250^{\circ} \mathrm{C}$ and $450^{\circ} \mathrm{C}(\sim 10 \%)$. For specimen $650^{\circ} \mathrm{C}$ and $850^{\circ} \mathrm{C}$ the increase is larger because the crack density is indeed larger and also 
because cracks are fully open, as seen by the permeability inversion which shows that for these samples, the crack aperture jumps almost one order of magnitude. In this case, the variation of crack density is larger during pressurization, thus a larger variation of $V_{p}$. In fact, the crack density $\rho$ is an indirect measure of the average crack length $\times$ number of cracks. For a given specimen, the variation of $\rho$ with pressure can only be interpreted as an average diminution of crack length (because the number of cracks remains constant) due to the increase of crack surface contact points. However, the increase of crack length with temperature treatment is harder to infer using wave velocities because both the average crack length and number increase. In this case, only our optical analysis can give bounds only for zero effective pressure (Fig. 9). However, in all cases, the permeability order of magnitude is controlled by the aperture and the jump between $450^{\circ} \mathrm{C}$ and $650^{\circ} \mathrm{C}$ samples is interpreted in a jump of crack average half aperture. However, the RT sample shows a decrease in aspect ratio and crack density, but a slight increase in crack aperture with effective pressure (Fig. 10c), which is counter-intuitive and probably shows the limitation of our microstructural inversion that neglects the important problem of crack connectivity. However, this could certainly be interpreted by introducing a percolation factor $f$ nonequal to 1 , which shows that the latter probably plays an important role at low effective pressures. The same observation can be performed in the case of the $650^{\circ} \mathrm{C}$ and $850^{\circ} \mathrm{C}$ samples, for which the crack aperture increases at low effective pressure while the aspect ratio and crack density decreases.

The excellent fit is a confirmation that the model, based on a network of cracks, is appropriate for this type of rock, which is consistent with previous experience with this type of hybrid experimental-modeling approach (BENSON et al., 2006). While this strategy does not predict permeability from base properties, the fact that the variation of permeability with pressure is driven almost solely by crack aspect ratio, the crack density and crack aperture thus allows important controls to be placed on how damage in rock masses (natural or induced) controls and affects transport properties. This has important implications in many areas of applied science and engineering, for example geothermal reservoir production and mining.

\section{Conclusions}

In this study a series of 20 heat-treated CCNBD samples of Westerly granite were tested in order to evaluate the effect of thermal damage on fracture toughness $\left(K_{I C}\right)$. Four heat-treated and one untreated cylindrical samples were tested in a Hoek type of cell, designed to measure contemporaneous permeability (up to $35 \mathrm{MPa}$ of effective pressure), elastic-wave velocity $\left(V_{p}, V_{s}\right)$ and porosity change as a function of effective pressure to $75 \mathrm{MPa}$. The decrease in P-wave velocity matched well with that of fracture toughness in samples heat-treated up to $850^{\circ} \mathrm{C}$. Crack densities $\rho$ obtained from wave-velocity inversion showed similar trend to that determined optically. Thermal cracking was found to induce a significant decrease in the mechanical and dynamic elastic properties, and to 
increase the permeability of Westerly granite of three orders of magnitude. Seismic wave velocity measurements are a good geophysical indicator of the damage and hence the deterioration of $K_{I C}$ and the enhancement of permeability with microcracking, and could be used as a nondestructive technique to monitor the evolution of these parameters in the laboratory and field. Permeability was estimated based on a method involving the GuÉGUEN and DiENEs (1989) crack permeability model, and prediction of the evolution of permeability with increasing pressure from elastic-wave velocity variations is in good agreement with the experimental data for the pressurization cycle. These constitute part of an ongoing research project endeavoring to link mechanical properties (fracture toughness, elastic constants) and physical properties (permeability, elastic-wave velocities) to quantitative microstructural parameters (crack density, aspect ratio).

\section{Acknowledgements}

This work was supported by a Canadian Foundation for Innovation (CFI) award to RPY, a Marie-Curie International Fellowship within the $6^{\text {th }}$ European Community Framework programme to PMB (Contract MOIF-CT-2005-020167) and an International Scientifique Collaboration Project (PICS) by the French National Scientific Research Agency (CNRS). The authors would like to thank D. Collins and Michael Heap (University College London) and an anonymous reviewer for the constructive remarks which helped to enhance this paper greatly.

\section{REFERENCES}

AtKinson, B.K. and Meredith, P.G., Experimental fracture mechanics data for rocks and minerals. In Fracture Mechanics of Rocks (ed. B. K. Atkinson) (Academic Press, London 1987) pp. 477-525.

Atkinson, B.K. (1984), Subcritical crack growth in geological materials, J. Geophys. Res. 89, 4077-114.

Balme, M.R., Rocchi, V., Jones, C., Sammonds, P.R., Meredith, P.G., and Boon, S. (2004), Fracture toughness measurements on igneous rocks using a high-pressure, high-temperature rock fracture mechanics cell, J. Volcanol. Geotherm. Res. 132(2-3), 159-172.

BAURE, S.J. and Johnson, B. (1979), Effects of slow uniform heating on the Westerly and Charcoal granites. Proc. $20^{\text {th }}$ Symp. On Rock Mechanics, Austin, Texas, 7-18. ASCE, New York.

Benson, P. Meredith, P., and Schubnel, A. (2006), Examining the role of void space fabric in permeability evolution with from statistics and percolation, J Geophys Res. (in press).

Brace, W.F., Walsh, J.B., and Frangos, T. (1968), Permeability of granite under pressure, J. Geophys. Res. 6 , 2225-2236.

Brace, W. and Martin, A. (1968), A test of law of effective stress for crystalline rocks of low porosity, Int. J, Rock Mech, Min. Sci. 5, 416-426.

Cheng, C.H. and Toksoz, M.N. (1979), Inversion of seismic velocities for the pore aspect ratio spectrum of a rock, J. Geophys. Res. 84, 7533-7543.

Darot, M., GuÉGuen, Y., and Baratin, M.-L. (1992), Permeability of thermally cracked granite, Geophys. Res. Le. 19(9), 869-872.

Engvik, A.K., Bertram, A., Kalthoff, J.F., Stockhert, B., Austrheim, H. and Elvevold, S. (2005), Magmadriven hydraulic fracturing and infiltration of into the damaged host rock, and example from Drowning Maud land, Antarctica, J. Structural Geol. 27, 839-854. 
FREDrich, J.T. and Wong, T.-F. (1986), Micromechanics of thermally induced cracking in three crustal rocks, J Geophy Res. 91, B12 12743-12764.

Funatsu, T., Seto, M., Shimada, H., Matsui, K., and Kuruppu, M. (2004), Combined effects of increasing temperature and confining pressure on the fracture toughness of clay-bearing rocks., Int. J. R. Mech. Min. Sci. 41, 927-938.

Gueguen, Y., and Dienes, J. (1988), Transport properties of rocks from statistics and percolation. J. Fath. Geol. $21,1,131$.

GuÉguen, Y. and Palciauskas, V. Introduction to the Physics of Rocks, 292 pp. (Princeton University Press, New Jersey 1994).

GuÉGuen, Y., and Schubnel, A. (2003), Elastic-wave velocities and permeability in cracked rocks, Tectonophysics 370, 163-176.

Hadley, K. (1976), Comparison of calculated and observed crack densities and seismic velocities in Westerly granite, J. Geophys. Res. 87, 9340-9348.

HeArd, H.C. and Page, L., (1982), Elastic moduli, thermal expansion and inferred permeability of two granites to $350^{\circ} \mathrm{C}$ and 55 Megapascals, J. Geophys. Res., 87, 9349-9348.

Heuze, F.E. (1983), High-temperature mechanical, physical and thermal properties of granitic rocks-A review, Int. J. Rock. Mech. Min. Sci. and Geomech. Abstr. 28 (1), 3-10.

ISRM (1995), Suggested method for determining Mode I fracture toughness using cracked chevron notched Brazilian disc (CCNBD) specimens, Int. J. Rock Mech. Min. Sci. Geomech. Abstr. 32, 57-64.

Kachanov, M. (1994), Elastic solids with many cracks and related problems, Adv. Appl. Mech. 30, $259-445$.

KERN, H. (1978), The effect of high temperature and high confining pressure on compressional wave velocities in quartz bearing and quartz free igneous and metamorphic rocks, Tectonophysics 44, 185-203.

Kern, H., Liu, B., and Popp, T. (1997), Relationship between anisotropy of P-and S- wave velocities and anisotropy of attenuation in serpentinite and amphibolite, J. Geophys. Res. 102, 3051-3065.

Launeau, P. and Robin, P.-YF. (1996), Fabric analysis using the intercept method., Tectonophysics 267(1-4), 91-119.

Le Ravalec, M. and GuÉGuen, Y. (1996), High and low frequency elastic moduli for a saturated porous/cracked rock-Differential self-consistent and poroelastic theories, Geophysics 61, 1080-1094.

Mavko, G. MukerJi, T., and Dvorkin, J. The Rock Physics Handbook (Cambridge University Press, 1999) 329 pp.

Meredith, P.G. and Atkinson, B.K. (1985), Fracture toughness and subcritical crack growth during hightemperature tensile deformation of Westerly granite and Black gabbro. Phys. Earth and Plan. Int. 39, 33-51.

Nasseri, M.H.B., Mohanty, B., and Robin, P.-YF. (2005), Characterization of microstructures and fracture toughness in five granitic rocks, Int. J. Rock Mech. Min. Sci. 42, 450-560.

Nasseri, M.H.B., Mohanty, B., and Young, R.P. (2006), Fracture toughness measurements and acoustic emission activity in brittle rocks, Pure Appl. Geophys. 163, 917-945.

NAsseri, M.H.B., Schubnel, A., and Young, R.P. (2007), Coupled evolutions of fracture toughness and elasticwave velocities at high crack density in thermally treated Westerly Granite, Int. J. Rock. Mech. and Min. Sci. 44(4), 601-616.

NASSERI, M.H.B. and Mohanty, B. (2008), Fracture toughness anisotropy in granitic rocks. J. Rock Mech. and Min. Sci. 45, 167-193.

Nasseri, M.H.B., Tatone, B.S.A., Grasseli, G. and Young, R.P. (2008), Fracture toughness and fracture roughness interrelationship in thermally treated Westerly granite (submitted to the same volume of special issue, Pure Appl. Geophys).

O’Connell, R., and Budiansky, B. (1974), Seismic velocities in dry and saturated rocks, J. Geophys. Res. 79, 5412-5426.

Reuschle., T., Gbaguidi Haore, S., and Darot, M. (2006), The effect of heating on microstructural evolution of La Peyratte granite deduced from acoustic velocity measurements, Earth Planet. Sci. Lett. 243, 692-700.

Rutqvist, J., Barr, D., Datta, R., Gens, A., Millard, S., Olivella, S., Tsang, C.-F and Tsang, Y. (2005), Coupled thermal-hydrological-mechanical analyses of the Yucca mountain shaft scale test-comparison of field measurements to predictions of four different numerical models, Int. J. Rock Mech. Min. Sci. 42, 680-697.

SAYERs, C.M. and KaChanov, M. (1995), Microcrack induced elastic wave anisotropy of brittle rocks. J. Geophys Res. 100, 4149-56. 
Schubnel, A, and Gueguen, Y. (2003), Anisotropy and dispersion in cracked rocks. J Geophys. Res. 108 art 2101.

Schubnel, A., and Benson, P.M., Thompson, B.D., Hazzard, J.F., and Young, R.P. (2006), Quantifying damage, saturation and anisotropy in cracked rocks by inverting elastic wave velocities, Pure Appl. Geophys. 163, 947-973.

Simmons, G., and Brace, W.F. (1965), Comparison of static and dynamic measurements of compressibility of rocks, J. Geophys. Res. 70, 5649-5656.

Thompson, B.D., Young, R.P., and Lockner, D.A. (2006), Fracture in Westerly granite under AE feedback and constant strain rate loading: nucleation, quasi-static propagation, and the transition to unstable fracture propagation, Pure Appl. Geophys. 163, 995-1019.

(Received June 19, 2008, revised January 27, 2009, accepted February 13, 2009)

To access this journal online:

www.birkhauser.ch/pageoph 